\title{
Host responses to pathogenic Salmonella infection
}

\author{
Bradley D. Jones \\ Department of Microbiology, University of Iowa, Iowa City, Iowa 52242 USA
}

Exposure to bacteria, fungi, and protozoa is an inescapable part of life from the moment that we are born until we die. Our contact with many of these microorganisms is very brief, whereas others stay behind and establish a more stable relationship. These organisms become part of our normal flora and are found, among other places, on the skin, in the mouth, and in the gastrointestinal tract. Typically these relationships are beneficial to both the host and the microorganism. Although the commensal flora appears to provide several benefits, it can also, under certain conditions, represent a significant threat to our health. The immune system has the primary responsibility of ensuring that the growth and location of commensal organisms is optimal for the host. If defensive immunity is compromised or fails in any way then benign commensals quickly become opportunistic pathogens.

Some of the microorganisms that we encounter rely upon their ability to cause cellular damage to a host for survival and replication. Upon entering a suitable host, these pathogens initiate a series of events that test innate host defense mechanisms and the capabilities of the immune system. From the perspective of the microorganism, these interactions challenge the ability of the bacteria to respond to constantly changing obstacles within the host environment. This review will focus on the interactions between virulent Salmonella strains and the hosts that they infect as an example of how selective pressure helps to shape host-pathogen relationships. Efforts will be made to highlight the various immunological and cellular host responses that occur in response to Salmonella infection and invasion.

Salmonella infections are initiated when a pathogenic strain is ingested into a suitable host via contaminated food or water. Ingested organisms move from the mouth to the extremely acidic environment of the stomach. Organisms that survive this low $\mathrm{pH}$ environment then move into the small intestine where they begin to compete with the normal enteric flora of the host for nutrients and space. The first pathogenic step of the bacteria is taken when organisms breach the intestinal epithelium of lymphoid follicles and enter the lymphatic sys-

Corresponding author.

E-MAIL bjones@blue.weeg.uiowa.edu; FAX (319) 335-9006. tem, sequentially moving from the Peyer's patch tissue to the lymph nodes and then to the spleen and liver. At each step of infection these pathogens respond to changing host environments by expressing appropriate factors that ensure their survival. The ability of these sophisticated pathogens to respond to changing host conditions places a heavy burden on the host as it must also adapt to ensure its own well being. Host cell responses to bacteria provide clues to the mechanisms used by the bacteria to infect the host and provide insight into possible mechanisms that the host might invoke to engage and eliminate the invading pathogens.

\section{Tissue culture cell responses to Salmonella}

Understanding the virulence mechanisms of bacterial pathogens depends upon the ability to directly examine host-bacterial interactions. Often, the lack of suitable models has made research on bacterial pathogens difficult. Fortunately, the development of an in vitro tissue culture model (Jones et al. 1981) has largely overcome this problem for the study of the role of Salmonella invasion in pathogenesis. Importantly, many of the interactions that occur between invasive Salmonellae and mammalian tissue culture cells duplicate the changes that have been observed by microscopy in Salmonellainfected host tissue (Takeuchi 1967; Finlay and Falkow 1990; Francis et al. 1992). In vitro tissue culture studies have identified some of the host cell responses that lead to Salmonella entry (or occur as a result of entry) and include actin rearrangement and polymerization at the host cell membrane, accumulation of cytoskeletal proteins at the site of bacterial entry, and calcium fluxes. A prominent, visible feature of the Salmonella entry process is the induction of membrane rearrangements or ruffles at the site of bacterial attachment (Ginocchio et al. 1992; Francis et al. 1993; Jones et al. 1993) (Fig. 1). These protrusions occur on the membrane at the site of bacterial attachment and are presumed to occur in direct response to a bacterial signal. Time-lapse video microscopy has demonstrated that these membrane ruffles erupt from the host cell within seconds of bacterial attachment to the cell. Subsequently, the columns of polymerized actin surround and enclose the organism. Within a short period of time, the entry signal peaks and, as it dissipates, the membrane ruffles return to the cell 
Figure 1. Cross-sectional confocal image of invasive $S$. typhimurium inducing actin rearrangement on $\mathrm{HEp}-2$ tissue culture cells as they enter the cell. Bacterial-induced membrane ruffles are composed of polymerized actin and are represented by areas of intense red. The bacteria are represented by white areas. These actin rearrangements typically move well beyond the bacterium, and as they resolve and return to the cell

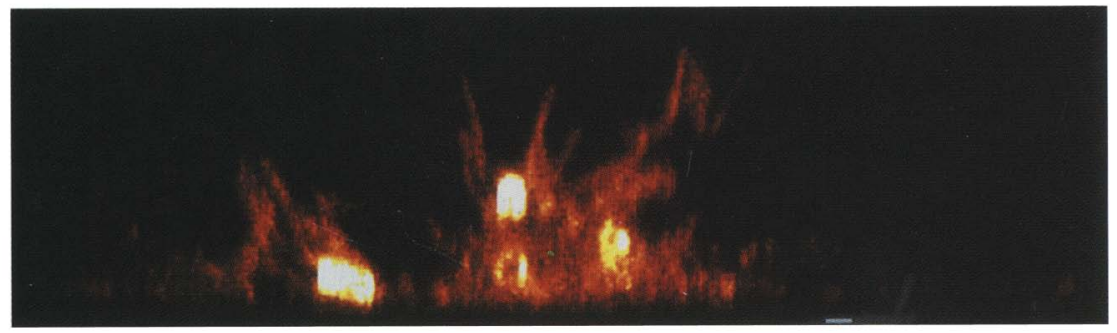
membrane, engulf and internalize the organism. Regions to the far left and far right of the photograph contain HEp-2 cells in the monolayer that are not being invaded and therefore actin staining is very diffuse. Scale bar, $1 \mathrm{~mm}$.

along with the enveloped bacterium (Francis et al. 1992). The formation of the membrane ruffles is dependent on actin monomer polymerization into microfilaments, as specific inhibitors (cytochalasins) (Tanenbaum 1978; Forscher and Smith 1988) of actin polymerization prevent membrane rearrangements and block Salmonella entry (Kihlström and Nilsson 1977; Finlay and Falkow 1988; Mroczenski-Wildey et al. 1989).

Efforts have been made to identify the signal transduction pathway of the cell that leads to uptake of the bacteria by using specific inhibitors. The protein kinase inhibitor genistein (Akiyama et al. 1987) blocks entry of Yersinia and enteropathogenic Escherichia coli into cells but has no effect on the invasion of Salmonella typhimurium into a variety of different cell lines (Rosenshine et al. 1992, 1994). Recent work has demonstrated that Listeria entry can be blocked by wortmannin and LY294002, inhibitors of phosphoinositide 3-kinase, but no effect was observed on $S$. typhimurium internalization (Ireton et al. 1996). These experiments have helped to identify signal transduction pathways that are not involved in Salmonella entry but have provided only limited information on the actual pathway that is stimulated.

Increased quantities of cytoskeletal proteins, in addition to actin, are also found at the site of bacterial entry. These proteins include $\alpha$-actinin, ezrin, talin, tropomyosin, and tubulin, although the mechanism of accumulation of these proteins is unknown (Finlay et al. 1991). The induction of intracellular calcium fluxes has also been reported in cells that have been exposed to invasive S. typhimurium (Ruschkowski et al. 1992; Pace et al. 1993). It is unknown whether these calcium changes are an integral part of the signal that leads to bacterial uptake or occur downstream of the entry event. Current research efforts are aimed at determining the precise mechanism by which Salmonella transmits an entry signal to the targeted cell and identifying the host cell signal pathway that is activated and results in cytoskeletal rearrangements and calcium fluxes.

\section{Intestinal epithelium responses to Salmonella}

The first specific interactions during natural infection between pathogenic Salmonella and a host occur at the epithelial surface of organized patches of lymphoid tis- sue or follicles that are scattered throughout the small intestine. This lymphoid tissue, also called Peyer's patches, has a specialized epithelium and an underlying dome that contains mature lymphocytes as well as developing lymphoblasts. The primary function of this tissue is believed to be immune surveillance of the gut. Invasive Salmonella strains specifically target these Peyer's patches for the initial penetration of the host small intestinal tissue. Early infection studies with mice demonstrated that virulent $S$. typhimurium, administered by an oral route, associated almost exclusively with Peyer's patch tissue of the terminal ileum (Carter and Collins 1974 ) as quickly as $3 \mathrm{hr}$ postinoculation (Hohmann et al. 1978). $M$ cells are specialized residents of the epithelium of lymphoid follicles and are interpersed within the epithelial layer of an intestinal lymphoid follicle at a ratio of approximately 1 per 10-20 enterocytes (Owen and Ermak 1990|. M cells have several distinctive characteristics that allow them to be identified easily (Owen and Jones 1974; Bockman 1983). These cells possess microvilli that are visibly shorter than those of enterocytes. They also lack a rigid cytoskeleton that allows migratory lymphocytes to deform and distort their cytoplasm. In addition, they have an elevated pinocytic activity that facilitates the uptake of intestinal microorganisms and particles. This suggests that a primary function of these cells is to transport and process luminal antigens to prime local intestinal immunity in the Peyer's patches (Jones et al. 1995). M cells also share similarities with other epithelial cells in that they form tight junctions with adjacent enterocytes and align along the basal lamina surface.

Because $M$ cells are unique to follicle-associated epithelia and $S$. typhimurium strains target lymphoid follicles for the initial penetration of host tissue, one strategy to study early interactions between Salmonella and host cells has been to look for interactions of the bacteria with $M$ cells at the earliest stages of infections. These studies typically utilize an intestinal ligated loop model system. In this system, a section of intestine of an anesthetized animal is tied off and injected with a pathogenic bacteria, which are then allowed to interact with the host tissue. Experiments using a murine-ligated model demonstrated that invasive $S$. typhimurium is able to locate and invade $M$ cells within the epithelium of the murine lymphoid follicles within $30 \mathrm{~min}$ of infection 
(Clark et al. 1994; Jones et al. 1994) (Fig. 2). The bacteria display a clear preference for $M$ cells, as no interactions can be detected with enterocytes at these early time points. Importantly, the entry of Salmonella into murine $M$ cells occurs by a membrane-ruffling mechanism that appears to be identical to Salmonella entry into tissue culture cells. The pathogenic effect of the bacteria on the tissue was increased at $60 \mathrm{~min}$ postinfection (Jones et al. 1994). Dying and disintegrating $M$ cells that contained bacteria were observed detaching from the mucosal surface. This damage allowed organisms that had been confined to the lumen of the small intestine access to underlying tissue. At later time points (120 and $180 \mathrm{~min}$ ), significant damage to the intestinal epithelium could be observed that included invasion of enterocytes, sloughing of large sections of epithelial cells, and penetration of significant numbers of bacteria into deeper tissues.

Experiments performed to determine whether the presence of invasive $S$. typhimurium in the murine in- testine has an effect on the cellular composition of Peyer's patches showed that the presence of the invasive pathogen caused a number of different host responses in the Peyer's patches (Savidge et al. 1991). The total number of $M$ cells increased in the follicle-associated epithelium as compared to uninfected mice, the average crypt depth lengthened, and the rate of enterocyte migration from the intestinal crypts increased. In addition, the numbers of $\mathrm{CD}^{+}$cells increased and $\mathrm{CD}^{+}$cells decreased. These results indicate that the damage illicited by invasive Salmonella induces a host response in the Peyer's patch tissue. Although the pathogen causes significant damage to the epithelium of lymphoid follicles at early points of infection, the findings of this study indicate that the host quickly replaces cells that have been damaged and/or destroyed. In addition, it is clear that the immune system is activated by and responds to the presence of Salmonella by activating both humoral and cellular immunity (Mastroeni et al. 1993).

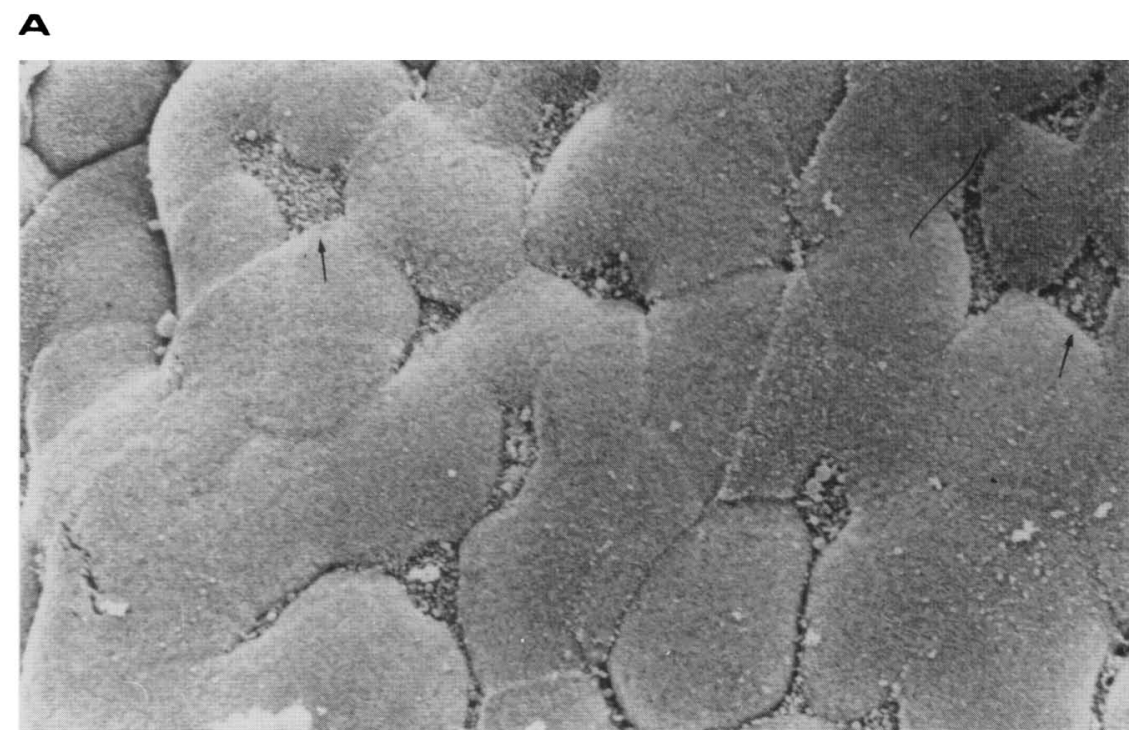

$\mathbf{B}$

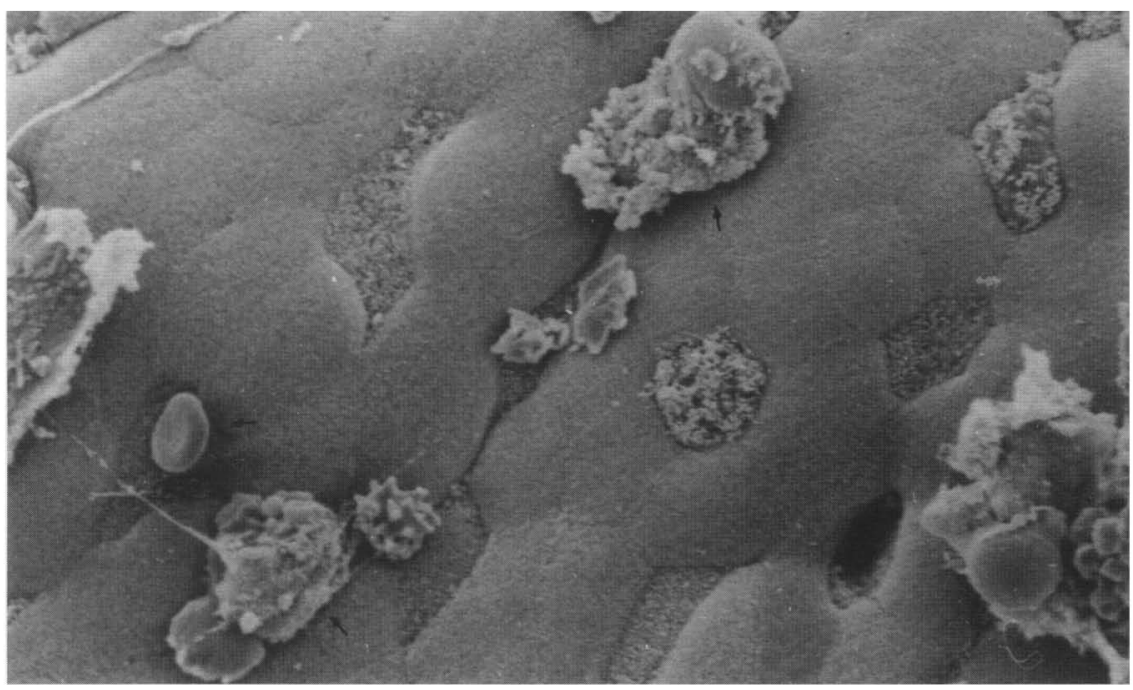

Figure 2. Scanning electron microscopy of the apical membrane of murine lymphoid follicles. (A) Uninfected Peyer's patch tissue. The $M$ cells have visibly different morphologies compared to the enterocytes, owing to the difference in the height of their microvilli. Two $\mathrm{M}$ cells are indicated by the arrows, although several other $M$ cells are also visible. Magnification, 2250x. (B) Murine intestinal tissue infected for 30 min with invasive $S$. typhimurium. Substantial membrane rearrangements are visible at the surface of the Peyer's patch. The cells with membrane rearrangements are $M$ cells, as interactions with enterocytes are not detected at this time point. The cell indicated by the arrow to the far left is clearly an $M$ cell and has a small, round ruffle protruding from the surface. Magnification, 2250x. 
These studies highlight the importance of correlating in vitro findings with in vivo observations. Salmonella entry into either $M$ cells or tissue culture cells occurs by a membrane-ruffling mechanism. However, the bacterial entry event typically does not kill tissue culture cells but clearly induces the death of $M$ cells that reside in the epithelium of Peyer's patches. Furthermore, in vivo studies of infection have provided first-hand observations of the progression of Salmonella infections that can result in systemic disease and the host cell response that leads to regeneration of host tissue and activation of immune defenses. Current research efforts are focused on understanding how and why invasive Salmonella selectively enter $M$ cells and determining the molecular mechanism of Salmonella-induced M cell death.

\section{Phagocytic cell responses and interactions}

Following passage through the intestinal epithelium of the Peyer's patch, invading organisms quickly enter the lymphatic system where interactions with professional killing cells determine the ultimate fate of the infection. These cells possess both oxygen-dependent and -independent killing mechanisms to kill internalized bacteria (Falkow et al. 1992). The production of toxic oxygen molecules such as superoxide, hydrogen peroxide, and hydroxy radicals that are pumped into the phagolysosome are the primary oxygen-dependent killing molecules of macrophages. The oxygen-independent killing mechanisms of the macrophages include acidification of the phagolysosome as well as secretion of small bactericidal peptides into the compartment.

Because the oxygen-dependent killing mechanisms of macrophages appear to have little effect on pathogenic Salmonella, the host is more dependent on oxygen-independent killing mechanisms. However, experimental evidence suggests that Salmonella has evolved mechanisms to circumvent or delay the killing activity of these mechanisms. For example, upon entry into macrophages, $S$. typhimurium delays significantly the fusion of the phagosome to the lysosome (Buchmeier and Heffron 1991). The majority of viable and dividing organisms observed by microscopy were found within unfused vacuoles, whereas nonpathogenic E. coli and dead Salmonella organisms were predominantly within fused phagolysosomes. Acidification of vacuoles containing live Salmonella organisms was delayed significantly $(4-5 \mathrm{hr})$ compared to vacuoles that contained dead organisms (Alpuche et al. 1992). The appearance of vacuole membrane markers, such as lysosomal membrane glycoprotein (lgp), Rab7, Rab9, cathepsin D, and mannose-6-phosphate receptor (M6PR), on normal and Salmonella-containing vacuoles has been monitored as a way to examine the effect of pathogenic Salmonella on phagolysosome maturation. These protein markers sequentially appear in (and disappear from) the membrane of an uninfected intracellular compartment as it matures from an endosome into a phagosome (Griffiths et al. 1988; Tooze et al. 1990; Chavrier et al. 1991). The early marker proteins lgp, Rab7, and Rab9 can be found on Salmo- nella-containing vesicles, but two later markers, cathepsin D and M6PR, are excluded (Jones and Falkow 1996). These results indicate that Salmonella begins to modify the vacuole in which it resides after early stages of vesicle maturation but before the appearance of the latestage markers cathepsin D and M6PR.

The growth state of $S$. typhimurium seems to change rapidly after entry into macrophages (Abshire and Neidhardt 1993). Immediately after entry of bacteria into phagocytic cells, the intracellular bacteria can be killed by treatment with chloramphenicol and ampicillin, which indicates that the bacteria are growing rapidly and require protein synthesis for survival. However, if the bacteria are allowed to reside within the cells for $2 \mathrm{hr}$ before treatment with the same antibiotics, the bacteria are no longer killed, although net growth is inhibited. This suggests that as infection time increases, the bacteria adapt to the intracellular environment of the macrophage and switch from a rapidly growing state to a survival mode that does not require protein synthesis. Collectively, the data indicate that upon entering the phagocytic vacuole, pathogenic Salmonella are intent on altering their environment by delaying and modifying the formation of the phagolysosome. Perhaps, these phagolysosome alterations are necessary to provide the bacteria sufficient time to alter their own physiological state in response to the intracellular environment of the macrophage. Future work is aimed at identifying the bacterial factors, and their mechanism of action, that leads to disruption of normal endosome maturation.

The PhoP/PhoQ is a two-component system that Salmonella encodes, which regulates its ability to cause systemic disease and to survive within the intracellular environment of phagocytic cells (Fields et al. 1989; Groisman et al. 1989; Miller et al. 1989). The PhoP protein is a transcriptional regulator and is a member of the OmpR subgroup of this protein family (Volz 1993). The PhoQ protein is a sensor protein that has two transmembrane domains and a periplasmic region in its predicted structure that may play a role in the sensing of environmental signals (Miller et al. 1989). The PhoP/PhoQ transcriptional regulon controls $\sim 40$ genes (Garcia-Vescovi et al. 1994) that are essential for various stages of Salmonella virulence, including resistance to host antimicrobial peptides (Groisman et al. 1992), passage or invasion through a host cell membrane (Behlau and Miller 1993; Bajaj et al. 1996), and the ability to adapt to and/or modify the phagolysosome (Alpuche et al. 1992). In fact, it appears that the majority of the virulence functions of Salmonella strains is regulated by the PhoP/PhoQ system. It seems fair to speculate that a primary role of this regulatory system is to monitor environmental signals from the host during infection to orchestrate a variety of bacterial survival strategies. In turn, it is likely that the host is responding in a similar fashion to the presence of the bacteria by activating tissue repair mechanisms and antibacterial killing mechanisms.

Recent work has indicated that virulent Salmonella induces the death of cultured macrophages (Lindgren et al. 1996). Moreover, it has been reported that death in 
cultured and bone marrow-derived macrophages occurs by an apoptotic mechanism based on nuclear morphology, cytoplasmic vacuolization, and cell DNA fragmentation (Chen et al. 1996; Monack et al. 1996). Programmed cell death was dependent on an intact bacterial invasion phenotype, as noninvasive $S$. typhimurium strains were unable to induce death. Currently it is not clear whether apoptosis benefits the pathogen by inactivating the professional killing cell or whether the host benefits by reducing the capacity of the bacteria to spread. Answers to those questions await future experimentation.

\section{Host immune responses to Salmonella infection}

Exposure to the human pathogen $S$. typhi usually results in acquired immunity to future infections. However, immunity may not develop if antibiotic treatment is received during the early stages of infection, suggesting that the immune system may require a prolonged exposure to the bacteria before a substantial defense can be mounted. Many studies have been performed to identify the principle components of the human immune response to typhoid fever. Adult volunteers who were administered the oral vaccine strain $S$. typhi Ty2la developed significant levels of circulating IgA and IgG antibodies that were directed against the lipopolysaccharide (LPS) of the organism (Forrest et al. 1991). In a Nepalese $S$. typhi vaccine field trial, subjects that developed serum antibody to the Vi capsular polysaccharide had a typhoid attack rate of only $4.1 \%$ compared to $16.2 \%$ for the control group, suggesting that circulating antibody levels participate in the initial resistance to infection (Acharya et al. 1987). Cell-mediated immunity is also observed in $S$. typhi-infected individuals (Tagliabue et al. 1985; Nencioni et al. 1987; Murphy et al. 1989). Although specific antigens that trigger the development of immunity have not been identified, it is believed that $\mathrm{CD}^{+}$cells, stimulated in response to the bacterial infection, activate professional killing cells. Thus, the primary line of defense against systemic Salmonella infection is presumed to be the activation of phagocytic cells.

Animal infection models have also been used extensively to study the immune response to Salmonella strains. The majority of this work has focused on the immune response to systemic infection of mice caused by $S$. typhimurium. Clearly, host resistance to Salmonella infection depends on a number of different factors. One gene that has received considerable attention has been designated Ity (also Lsh and Bcg). Mice that are Itydefective $\left\langle\right.$ Ity $^{\mathrm{s}}$ ) are significantly more susceptible to pathogenic Salmonella than are Ity ${ }^{\mathrm{r}}$ animals. The molecular mechanism for this difference in resistance to the bacteria is unknown, although Ity ${ }^{\mathrm{s}}$ mice permit low numbers of bacteria to proliferate rapidly to high levels in the spleen and liver while much higher inocula are required to allow net growth of Salmonella in Ity $^{\mathrm{r}}$ mice. One possible explanation for these growth differences in mice is provided by in vitro studies. Resident phagocytic cells from Ity ${ }^{\mathrm{s}}$ and Ity $^{\mathrm{r}}$ mice were isolated and examined for their ability to kill intracellular bacteria (van Dissel et al. 1985, 1986). Phagocytic cells from the Ity ${ }^{\mathrm{r}}$ mice killed intracellular Salmonellae at a much higher rate than the cells from the Ity ${ }^{s}$ mice. The mechanism of bacterial killing has not yet been elucidated, although macrophages from the Ity ${ }^{\mathrm{r}}$ mice had enhanced expression of the activated macrophage markers Ia and Acm-1 (Buschman et al. 1989). In addition, the cells produced increased levels of oxygen- and nitrogen-free radicals in response to the activator $\gamma$ interferon (IFN- $\gamma$ ) (Skamene and Pietrangeli 1991).

The gene responsible for the Ity phenotype recently has been cloned and sequenced from the mouse and designated Nramp (natural resistance-associated macrophage protein)(Vidal et al. 1993; Malo et al. 1994). Structural analysis of the Nramp protein sequence suggests that the molecule is a membrane transporter, although no transport function has been demonstrated yet (Cellier et al. 1996). Another member of the Nramp gene family, the Saccharomyces cerevisiae protein SMF1, has been shown to be a manganese transporter, which suggests that this protein family may be a new class of membrane transporters or channels (Supek et al. 1996). Northern blot analysis has demonstrated that the Nramp mRNA is expressed exclusively in macrophages derived from lymphoid organs as well as from macrophage tissue culture lines such as J774 (Vidal et al. 1993). Transfection of the Nramp gene into RAW 264.7 tissue culture macrophages resulted in increases in the respiratory burst, nitrite release, and uptake of L-arginine, all of which are indicators of macrophage activation (Barton et al. 1995). The Nramp gene, which plays a role in regulating expression of interleukin- $1 \beta$, inducible nitric oxide synthase, maphistocomputability (MHC) class II molecules, and tumor necrosis factor $\alpha(\mathrm{TNF} \alpha)$ levels is thought to exert its activity early in the macrophage activation pathway (Blackwell et al. 1994; Skamene 1994; Blackwell 1996). Future experimentation should elucidate the function of the Nramp protein and how this function translates into macrophage activation and immunity. However, it is clear that the Nramp protein is important in the activation of macrophages at an early stage and that this activation is important in the elimination of intracellular pathogens such as Salmonella, Mycobacteria, and Leishmania from an infected host.

Mice with an Ity ${ }^{\mathrm{s}}$ background have been useful in the study of the specific host immune response to virulent Salmonella infection. Antibody-mediated and cell-mediated immunity are both required for long-term protection against infection with pathogenic Salmonella strains in Ity ${ }^{\mathrm{s}}$ mice, whereas innately resistant mice respond to Salmonella infection with a nonspecific immune response (Collins 1974; Hormaeche et al. 1990; Mastroeni et al. 1993). Presumably, a part of these different immune responses are attributable to different levels of IFN- $\gamma$ that are produced. Two different groups have found that Ity ${ }^{\mathrm{s}}$ mice produce significantly lower levels of IFN- $\gamma$ than Ity ${ }^{\mathrm{r}}$ mice (Freudenberg et al. 1991; 
Kita et al. 1992). One group performed a study to identify which cells might be responsible for the difference in IFN- $\gamma$ production. They demonstrated that murine natural killer cells from wild-type $\left(\right.$ Ity $\left.^{T}\right)$ mice infected with $S$. typhimurium were stimulated to produce IFN- $\gamma$. In contrast, Salmonella-infected natural killer cells from Ity ${ }^{\mathrm{s}}$ mice produced relatively little IFN- $\gamma$ (Ramarathinam et al. 19931.

IFN- $\gamma$ and TNF $\alpha$ play important roles in a variety of specific and general immune responses. Each of these cytokines plays a role in activating host immunity in response to virulent Salmonella infection. Treatment of tissue culture cells with IFN- $\gamma$ or TNF $\alpha$ decreases the susceptibility of the cells to Salmonella-induced membrane rearrangements and entry (Degre et al. 1989). Pretreatment of cultured macrophages with IFN- $\gamma$ has been shown to activate killing mechanisms of professional phagocytes, as evidenced by increased fusion of phagosomes containing bacteria with lysosomes (Ishibashi and Arai 1990). Experimental data suggest that a primary function of IFN- $\gamma$ is to limit the growth of $S$. typhimurium early in the infection of mice (Muotiala and Makela 1990; Nauciel and Espinasse 1992). Mice injected with exogenous IFN- $\gamma$ at early stages of infection with pathogenic $S$. typhimurium had fewer numbers of bacteria in the lymphatic organs than control mice. However, when IFN- $\gamma$ was administered at later stages, it had no detectable effect on the course of the infection. Reciprocally, when circulating levels of IFN- $\gamma$ were depleted in mice by the injection of anti-IFN- $\gamma$ antibody, mice were unable to prevent even very low numbers of $S$. typhimurium from proliferating and inducing septic shock. In addition, mice that have a mutation in the gene encoding IFN- $\gamma$ (IFN- $\gamma$ knockout or $\mathrm{GKO}^{-}$mice), and are therefore unable to produce IFN- $\gamma$, are hypersusceptible to infection with virulent $S$. typhimurium (Hess et al. 1996). The observation that the lymphoid cells of Peyer's patches are stimulated to produce large quantities of IFN- $\gamma$ in response to the presence of Salmonella is indicative that the host depends on IFN- $\gamma$-mediated effects early in infection for activation of nonspecific defensive mechanisms (Ramarathinam et al. 1991).

Additional experiments have established that TNF $\alpha$ plays a significant role in the host cell response to $S$. typhimurium (Nakano et al. 1990). Administration of TNF $\alpha$ to mice inoculated with $S$. typhimurium reduced the numbers of bacteria that could be recovered from the animals compared to untreated controls. In addition, injection of TNF $\alpha$ improved the survival rate of mice receiving pathogenic Salmonella. As observed for IFN- $\gamma$, depletion of TNF $\alpha$ in mice with anti-TNF $\alpha$ antibodies decreased the dose of bacteria required to achieve a lethal systemic infection in mice. Also, treatment of phagocytes with anti-TNF $\alpha$ antibodies blocked LPS-stimulated activation. These data suggest that TNF $\alpha$ is produced as the result of two separate signals; the LPS of the infecting Salmonella organisms and tissue damage that results from invasion and destruction of host cells. Clearly, the ability of the host to produce IFN- $\gamma$ and TNF $\alpha$ in response to the presence of Salmonella is criti- cal. Presumably, these two lymphokines function by activating early nonspecific killing mechanisms of professional phagocytes, as their activity is most important at the initial stages of Salmonella infection. A specific effect of IFN- $\gamma$ on macrophages has been identified, which is to increase the level of phagosome-lysosome fusion in the cell. Increased levels of endosome maturation would protect the host by neutralizing efforts by Salmonella increase survival by delaying fusion. Research efforts continue to define these processes more clearly as well to identify other activities of IFN- $\gamma$ and TNF $\alpha$ in host immunity.

The specific immune response to pathogenic S. typhimurium appears to result in a general host immunosuppression (Lee et al. 1985). Mice that have been immunized previously with $S$. typhimurium have been examined for their ability to mount immune responses to other antigens or pathogens (Lee et al. 1985). Those experiments revealed that immunized mice are unable to respond to new antigens for up to 3 weeks after immunization with $S$. typhimurium. Apparently, macrophages are primarily responsible for this inability to respond to new antigenic challenge, as in vitro depletion of phagocytes eliminated the observed immunosuppression. Further work revealed that large quantities of nitric oxide, produced by activated macrophages, inactivated lymphocytes, thereby reducing the capacity of the immune system to mount a cellular response to antigens. Treatment of mice with IL-4 or anti-IFN- $\gamma$ antibody prevented Salmonella-induced immunosuppression by preventing nitric oxide poisoning of lymphocytes (al-Ramadi et al. 1992).

\section{Conclusion}

The focus of this review has been the host response to Salmonella infection and virulence mechanisms. The first significant interactions between the bacteria and the host occur at the lymphoid follicles of the intestine. This action would seem to play into the hands of the host because the primary function of lymphoid follicles is to protect the host from intestinal invasion. However, Salmonella displays a highly evolved ability not only to initiate contact with the host at Peyer's patches but to benefit from the interaction. Subsequently, the bacteria move into the lymphatic system where the survival of the organisms requires the ability to productively interact with professional killing cells. Again, these pathogens display a remarkable adaption to an environment that is considered to be very hostile. Thus, it is apparent that the bacteria have discovered that survival within the host depends on their ability to directly engage the host immune system and alter the host response in their favor. It seems certain that the pressure being exerted by this and other bacterial pathogens is honing the host response to infection. It is also clear that the bacteria will not be left behind in the evolutionary battle. From a scientific point of view, these interactions offer the opportunity to gain insights both into cell biology and bacterial pathogenicity. 


\section{Acknowledgments}

Thanks go to Nitin Mathur for providing the scanning electron micrographs. B. Jones is supported by U.S. Public Health Service grant AI38268 and a grant from the Roy J. Carver Charitable Trust.

\section{References}

Abshire, K.Z. and F.C. Neidhardt. 1993. Growth rate paradox of Salmonella typhimurium within host macrophages. I. Bacteriol. 175: 3744-3748.

Acharya, I.L., C.U. Lowe, R. Thapa, V.L. Gurubacharya, M.B. Shrestha, M. Cadoz, D. Schulz, J. Armand, D.A. Bryla, B. Trollfors, T. Cramton, R. Schneerson, and J.B. Robbins. 1987. Prevention of typhoid fever in Nepal with the Vi capsular polysaccharide of Salmonella typhi. A preliminary report. N. Engl. J. Med. 317: 1101-1104.

Akiyama, T., J. Ishida, S. Nakagawa, H. Ogawara, S. Watanabe, N. Itoh, M. Shibuya, and Y. Fukami. 1987. Genistein, a specific inhibitor of tyrosine-specific protein kinases. J. Biol. Chem. 262: 5592-5595.

al-Ramadi, B.K., J.J.J. Meissler, D. Huang, and T.K. Eisenstein. 1992. Immunosuppression induced by nitric oxide and its inhibition by interleukin-4. Eur. J. Immunol. 22: 2249-2254.

Alpuche, A.C., J.A. Swanson, W.P. Loomis, and S.I. Miller. 1992. Salmonella typhimurium activates virulence gene transcription within acidified macrophage phagosomes. Proc. Natl. Acad. Sci. 89: 10079-10083.

Bajaj, V., R.L. Lucas, C. Hwang, and C.A. Lee. 1996. Co-ordinate regulation of Salmonella typhimurium invasion genes by environmental and regulatory factors is mediated by control of hilA expression. Mol. Microbiol. 22: 703-714.

Barton, C.H., S.H. Whitehead, and J.M. Blackwell. 1995. Nramp transfection transfers Ity/Lsh/Bcg-related pleiotropic effects on macrophage activation: Influence on oxidative burst and nitric oxide pathways. Mol. Med. 1: 267-279.

Behlau, I. and S.I. Miller. 1993. A PhoP-repressed gene promotes Salmonella typhimurium invasion of epithelial cells. J. Bacteriol. 175: 4475-4484.

Blackwell, J.M. 1996. Structure and function of the natural-resistance-associated macrophage protein (Nrampl), a candidate protein for infectious and autoimmune disease susceptibility. Mol. Med. Today 2: 205-211.

Blackwell, J.M., C.H. Barton, J.K. White, T.I. Roach, M.A. Shaw, S.H. Whitehead, B.A. Mock, S. Searle, H. Williams, and A.M. Baker. 1994. Genetic regulation of leishmanial and mycobacterial infections: The Lsh/Ity/Bcg gene story continues. Immunol. Lett. 43: 99-107.

Bockman, D.E. 1983. Functional histology of appendix. Arch. Histol. Ipn. 46: 271-292.

Buchmeier, N.A. and F. Heffron. 1991. Inhibition of macrophage phagosome-lysosome fusion by Salmonella typhimurium. Infect. Immunol. 59: 2232-2238.

Buschman, E., T. Taniyama, R. Nakamura, and E. Skamene. 1989. Functional expression of the Bcg gene in macrophages. Res. Immunol. 140: 793-797.

Carter, P.B. and F.M. Collins. 1974. The route of enteric infection in normal mice. I. Exp. Med. 139: 1189-1203.

Cellier, M., A. Belouchi, and P. Gros. 1996. Resistance to intracellular infections: Comparative genomic analysis of Nramp. Trends Genet. 12: 201-204.

Chavrier, P., J.P. Gorvel, E. Stelzer, K. Simons, J. Gruenberg, and M. Zerial. 1991. Hypervariable C-terminal domain of rab proteins acts as a targeting signal. Nature 353: 769-772.

Chen, L.M., K. Kaniga, and J.E. Galan. 1996. Salmonella spp. are cytotoxic for cultured macrophages. Mol. Microbiol. 21: 1101-1115.

Clark, M.A., M.A. Jepson, N.L. Simmons, and B.H. Hirst. 1994. Preferential interaction of Salmonella typhimurium with mouse Peyer's patch M cells. Res. Microbiol. 145: 543-552.

Collins, F.M. 1974. Vaccines and cell-mediated immunity. Bacteriol. Rev. 38: 371-402.

Degre, M., G. Bukholm, and C.W. Czamlecki. 1989. In vitro treatment of HEp-2 cells with human tumor necrosis factor-alpha and human interferons reduces invasiveness of Salmonella typhimurium. I. Biol. Regul. Homeost. Agents 3: $1-7$.

Falkow, S., R.R. Isberg, and D.A. Portnoy. 1992. The interaction of bacteria with mammalian cells. Annu. Rev. Cell Biol. 8: 333-363.

Fields, P.I., E.A. Groisman, and F. Heffron. 1989. A Salmonella locus that controls resistance to microbicidal proteins from phagocytic cells. Science 243: 1059-1062.

Finlay, B.B. and S. Falkow. 1988. Comparison of the invasion strategies used by Salmonella cholerae-suis, Shigella flexneri and Yersinia enterocolitica to enter cultured animal cells: Endosome acidification is not required for bacterial invasion or intracellular replication. Biochimie 70: 1089-1099.

- 1990. Salmonella interactions with polarized human intestinal Caco-2 epithelial cells. I. Infect. Dis. 162: 10961106.

Finlay, B.B., S. Ruschkowski, and S. Dedhar. 1991. Cytoskeletal rearrangements accompanying Salmonella entry into epithelial cells. I. Cell. Sci. 99: 283-296.

Forrest, B.D., J.T. LaBrooy, L. Beyer, C.E. Dearlove, and D.J. Shearman. 1991. The human humoral immune response to Salmonella typhi Ty21a. J. Infect. Dis. 163: 336-345.

Forscher, P. and S.J. Smith. 1988. Actions of cytochalasins on the organization of actin filaments and microtubules in a neuronal growth cone. J. Cell. Biol. 107: 1505-1516.

Francis, C.L., M.N. Starnbach, and S. Falkow. 1992. Morphological and cytoskeletal changes in epithelial cells occur immediately upon interaction with Salmonella typhimurium grown under low-oxygen conditions. Mol. Microbiol. 6: $3077-3087$.

Francis, C.L., T.A. Ryan, B.D. Jones, S.J. Smith, and S. Falkow. 1993. Ruffles induced by Salmonella and other stimuli direct macropinocytosis of bacteria. Nature 364: 639-642.

Freudenberg, M.A., Y. Kumazawa, S. Meding, J. Langhorne, and C. Galanos. 1991. Gamma interferon production in endotoxin-responder and -nonresponder mice during infection. Infect. Immun. 59: 3484-3491.

Garcia-Vescovi, E., F. Soncini, and E.A. Groisman. 1994. The role of the PhoP/PhoQ regulon in Salmonella virulence. Res. Microbiol. 145: 473-480.

Ginocchio, C., J. Pace, and J.E. Galán. 1992. Identification and molecular characterization of a Salmonella typhimurium gene involved in triggering the internalization of salmonellae into cultured epithelial cells. Proc. Natl. Acad. Sci. 89: 5976-5980.

Griffiths, G., B. Hoflack, K. Simons, I. Mellman, and S. Kornfeld. 1988. The mannose 6-phosphate receptor and the biogenesis of lysosomes. Cell 52: 329-341.

Groisman, E.A., E. Chiao, C.J. Lipps, and F. Heffron. 1989. Salmonella typhimurium phoP virulence genes is a transcriptional regulator. Proc. Nat1. Acad. Sci. 86: 7077-7081.

Groisman, E.A., C. Parra-Lopez, M. Salcedo, C.J. Lipps, and F. Heffron. 1992. Resistance to host antimicrobial peptides is necessary for Salmonella virulence. Proc. Natl. Acad. Sci. 89: 11939-11943. 
Hess, J., C. Ladel, D. Midko, and S.H. Kaufmann. 1996. Salmonella typhimurium aroA- infection in gene-targeted immunodeficient mice: Major role of $\mathrm{CD}^{+}{ }^{+} \mathrm{TCR}$-alpha beta cells and IFN-gamma in bacterial clearance independent of intracellular location. J. Immunol. 156: 3321-3326.

Hohmann, A.W., G. Schmidt, and D. Rowley. 1978. Intestinal colonization and virulence of Salmonella in mice. Infect. Immun. 22: 763-770.

Hormaeche, C.E., P. Mastoeni, A. Arena, J. Uddin, and H.S. Joysey. 1990. T-cells do not mediate the early suppression of a salmonella infection in the RES. Immunology 70: 247250.

Ireton, K., B. Payrastre, H. Chap, W. Ogawa, H. Sakaue, M. Kasuga, and P. Cossart. 1996. A role for phosphoinositide 3-kinase in bacterial invasion. Science 274: 780-782.

Ishibashi, Y. and T. Arai. 1990. Specific inhibition of phagosome-lysosome fusion in murine macrophages mediated by Salmonella typhimurium infection. FEMS Microbiol. Immunol. 2: 35-43.

Jones, B.D. and S. Falkow. 1996. Typhoid fever: Host immune response and Salmonella virulence determinants. Annu. Rev. Immunol. 14: 533-561.

Jones, B.D., H.F. Paterson, A. Hall, and S. Falkow. 1993. Salmonella typhimurium induces membrane ruffling by a growth factor receptor independent mechanism. Proc. Natl. Acad. Sci. 90: 10390-10394.

Jones, B.D., N. Ghori, and S. Falkow. 1994. Salmonella typhimurium initiates murine infection by penetrating and destroying the specialized epithelial $M$ cells of the Peyer's patches. I. Exp. Med. 180: 15-23.

Jones, B., L. Pascopella, and S. Falkow. 1995. Entry of microbes into the host: Using $M$ cells to break the mucosal barrier. Curr. Opin. Immunol. 7: 474-478.

Jones, G.W., L.A. Richardson, and D. Uhlman. 1981. The invasion of HeLa cells by Salmonella typhimurium: Reversible and irreversible bacterial attachment and the role of bacterial motility. J. Gen. Microbiol. 127: 351-360.

Kihlström, E. and L. Nilsson. 1977. Endocytosis of Salmonella typhimurium $395 \mathrm{MS}$ and MR 10 by HeLa cells. Acta. Pathol. Microbiol. Scand. 85: 322-328.

Kita, E., M. Emoto, D. Oku, F. Nishikawa, A. Hamuro, N. Kamikaidou, and S. Kashiba. 1992. Contribution of interferon gamma and membrane-associated interleukin 1 to the resistance to murine typhoid of Ityr mice. I. Leukocyte Biol. 51: 244-250.

Lee, J.C., C.W. Gibson, and T.K. Eisenstein. 1985. Macrophagemediated mitogenic suppression induced in mice of the $\mathrm{C} 3 \mathrm{H}$ lineage by a vaccine strain of Salmonella typhimurium. Cell. Immunol. 91: 75-91.

Lindgren, S.W., I. Stojilikovic, and F. Heffron. 1996. Macrophage killing is an essential virulence mechanism of Salmonella typhimurium. Proc. Nat1. Acad. Sci. 93: 4197-4201.

Malo, D., K. Vogan, S. Vidal, J. Hu, M. Cellier, E. Schurr, A. Fuks, N. Bumstead, K. Morgan, and P. Gros. 1994. Haplotype mapping and sequence analysis of the mouse Nramp gene predict susceptibility to infection with intracellular parasites. Genomics 23: 51-61.

Mastroeni, P., B. Villarreal-Ramos, and C.E. Hormaeche. 1993. Adoptive transfer of immunity to oral challenge with virulent Salmonellae in innately susceptible BALB/c mice requires both immune serum and $\mathrm{T}$ Cells. Infect. Immun. 61: 3981-3984.

Miller, S.I., A.M. Kurkal, and J.J. Mekalanos. 1989. A twocomponent regulatory system (phoP phoQ) controls Salmonella typhimurium virulence. Proc. Natl. Acad. Sci. 86: 5054-5058.
Monack, D.M., B. Raupach, A.E. Hromockyj, and S. Falkow. 1996. Salmonella typhimurium invasion induces apoptosis in infected macrophages. Proc. Natl. Acad. Sci. 93: 98339838.

Mroczenski-Wildey, M.J., J.L. Di Fabio, and F.C. Cabello. 1989. Invasion and lysis of HeLa cell monolayers by Salmonella typhi: The role of lipopolysaccharide. Microb. Pathog. 6: 143-152.

Muotiala, A. and P.H. Makela. 1990. The role of IFN-gamma in murine Salmonella typhimurium infection. Microb. Pathog. 8: $135-141$.

Murphy, J.R., S.S. Wasserman, S. Baqar, L. Schlesinger, C. Ferreccio, A.A. Lindberg, and M.M. Levine. 1989. Immunity to Salmonella typhi: Considerations relevant to measurement of cellular immunity in typhoid-endemic regions. Clin. Exp. Immunol. 75: 228-233.

Nakano, Y., K. Onozuka, Y. Terada, H. Shinomiya, and M. Nakano. 1990. Protective effect of recombinant tumor necrosis factor-alpha in murine salmonellosis. I. Immunol. 144: 1935-1941.

Nauciel, C. and M.F. Espinasse. 1992. Role of gamma interferon and tumor necrosis factor alpha in resistance to Salmonella typhimurium infection. Infect. Immun. 60: 450-454.

Nencioni, L., L. Villa, M.T. De Magistris, M. Romano, D. Boraschi, and A. Tagliabue. 1987. Cellular immunity against Salmonella typhi after live oral vaccine. Adv. Exp. Med. Biol. 216B: 1669-1675.

Owen, R.L. and T.H. Ermak. 1990. Structural specializations for antigen uptake and processing in the digestive tract. Springer Semin. Immunopathol. 12: 139-152.

Owen, R.L. and A.L. Jones. 1974. Epithelial cell specialization within human Peyer's patches: An ultrastructural study of intestinal lymphoid follicles. Gastroenterology 66: 189-203.

Pace, J., M.J. Hayman, and J.E. Galán. 1993. Signal transduction and invasion of epithelial cells by $\mathrm{S}$. typhimurium. Cell 72: $505-514$.

Ramarathinam, L., R.A. Shaban, D.W. Niesel, and G.R. Klimpel. 1991. Interferon gamma (IFN-gamma) production by gut-associated lymphoid tissue and spleen following oral Salmonella typhimurium challenge. Microb. Pathog. 11: 347-356.

Ramarathinam, L., D.W. Niesel, and G.R. Klimpel. 1993. Ity influences the production of IFN- $\gamma$ by murine splenocytes stimulated in vitro with Salmonella typhimurium. I. Immunol. 150: 3965-3972.

Rosenshine, I., V. Duronio, and B.B. Finlay. 1992. Tyrosine protein kinase inhibitors block invasin-promoted bacterial uptake by epithelial cells. Infect. Immun. 60: 2211-2217.

Rosenshine, I., S. Ruschkowski, V. Foubister, and B.B. Finlay. 1994. Salmonella typhimurium invasion of epithelial cells: Role of induced host cell tyrosine protein phosphorylation. Infect. Immun. 62: 4969-4974.

Ruschkowski, S., I. Rosenshine, and B.B. Finlay. 1992. Salmonella typhimurium induces an inositol phosphate flux in infected epithelial cells. FEMS Microbiol. Lett. 74: 121-126.

Savidge, T.C., M.W. Smith, P.S. James, and P. Aldred. 1991. Salmonella-induced $\mathrm{M}$-cell formation in germ-free mouse Peyer's patch tissue. Am. I. Pathol. 139: 177-184.

Skamene, E. 1994. The Bcg gene story. Immunobiology 191: 451-460.

Skamene, E. and C.E. Pietrangeli. 1991. Genetics of the immune response to infectious pathogens. Curr. Opin. Immunol. 3: 511-517.

Supek, F., L. Supekova, H. Nelson, and N. Nelson. 1996. A yeast manganese transporter related to the macrophage protein involved in conferring resistance to mycobacteria. Proc. Natl. Acad. Sci. 93: 5105-5110. 
Tagliabue, A., L. Nencioni, A. Caffarena, L. Villa, D. Boraschi, G. Cazzola, and S. Cavalieri. 1985. Cellular immunity against Salmonella typhi after live oral vaccine. Clin. Exp. Immunol. 62: 242-247.

Takeuchi, A. 1967. Electron microscope studies of experimental Salmonella infection. I. Penetration into the intestinal epithelium by Salmonella typhimurium. Am. I. Pathol. 50: 109-136.

Tanenbaum, S.W., ed. 1978. Cytochalasins: Biochemical and cell biological aspects. North-Holland, New York, NY.

Tooze, J., M. Hollinshead, T. Ludwig, K. Howell, B. Hoflack, and H. Kern. 1990. In exocrine pancreas, the basolateral endocytic pathway converges with the autophagic pathway immediately after the early endosome. J. Cell. Biol. 111: 329345.

van Dissel, J., P.C. Leijh, and F.R. van Furth. 1985. Differences in initial rate of intracellular killing of Salmonella typhimurium by resident peritoneal macrophages from various mouse strains. I. Immunol. 134: 3404-3410.

van Dissel, J., J.J. Stikkelbroeck, W. Sluiter, P.C. Leijh, and F.R. van Furth. 1986. Differences in initial rate of intracellular killing of Salmonella typhimurium by granulocytes of Salmonella-susceptible C57BL/10 mice and Salmonella-resistant CBA mice. J. Immunol. 136: 1074-1080.

Vidal, S.M., D. Malo, K. Vogan, E. Skamene, and P. Gros. 1993. Natural resistance to infection with intracellular parasites: Isolation of a candidate for Bcg. Cell 73: 469-485.

Volz, K. 1993. Structural conservation in the CheY superfamily. Biophys. J. 32: 11741-11753. 


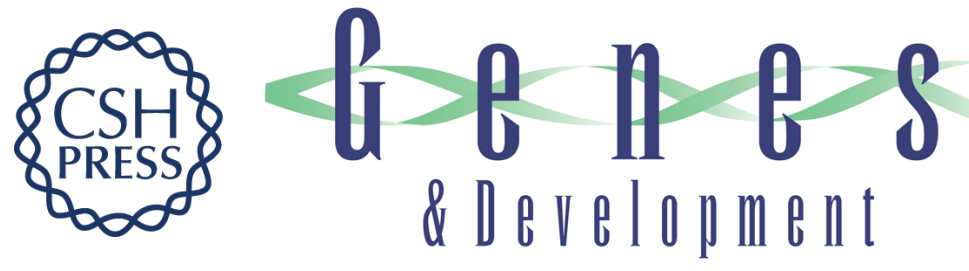

\section{Host responses to pathogenic Salmonella infection.}

B D Jones

Genes Dev. 1997, 11:

Access the most recent version at doi:10.1101/gad.11.6.679 $\begin{array}{ll}\text { References } & \begin{array}{l}\text { This article cites } 78 \text { articles, } 32 \text { of which can be accessed free at: } \\ \text { http://genesdev.cshlp.org/content/11/6/679.full.html\#ref-list-1 }\end{array}\end{array}$

License

Email Alerting

Receive free email alerts when new articles cite this article - sign up in the box at the top Service right corner of the article or click here.

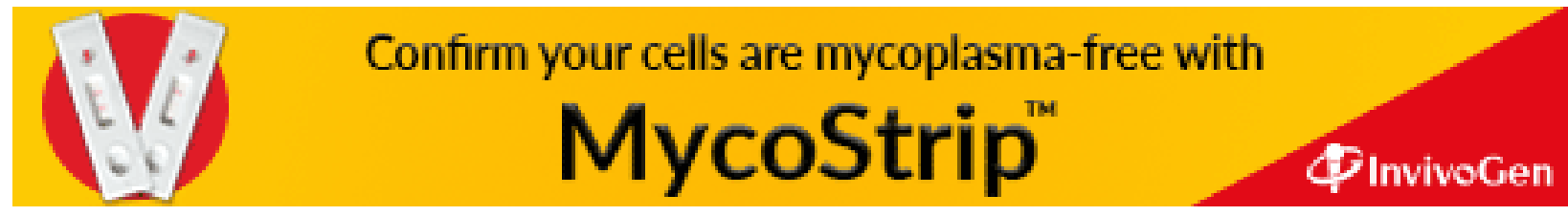

